\title{
Academic dishonesty amongst Australian criminal justice and policing university students: individual and contextual factors

\author{
Li Eriksson ${ }^{*}$ and Tara Renae McGee
}

\author{
* Correspondence: \\ l.eriksson@griffith.edu.au \\ School of Criminology and Criminal \\ Justice, Griffith University, Qld, \\ Australia
}

\begin{abstract}
Over the past few decades, a body of research has developed examining the academic dishonesty of university and college students. While research has explored academic dishonesty amongst American criminal justice and policing students, no research has specifically focused on investigating the dynamics and correlates of academic dishonesty amongst Australian criminology students. This study drew upon data obtained from a survey of 79 undergraduate criminal justice and policing students studying at an Australian university. Overall, the results suggest that male gender, viewing academic dishonesty as less serious and holding justifications for engaging in this type of behaviour were significant predictors of self-reported academic dishonesty. The findings suggest that more proactive strategies need to be implemented by universities to prevent student involvement in academic dishonesty.
\end{abstract}

Keywords: Academic dishonesty; University students; Criminal justice students; Policing students

\section{Background}

Empirical research has shown that academic dishonesty among students is both a prevalent and growing problem in colleges and universities around the world (Allen et al. 1998; Hrabak et al. 2004; Lambert and Hogan 2004; Marsden et al. 2005; McCabe et al. 2008; McCabe and Trevino 1996). In addition to demonstrating the prevalence of academic dishonesty, studies have shown that there are many individual characteristics and contextual factors that may underpin the prevalence of academic misconduct (Lambert and Hogan 2004; McCabe et al. 2001; Whitley and Keith-Spiegel 2002). Research further shows that prevalence rates and predictors may differ across disciplines (Iyer and Eastman 2006; Lambert and Hogan 2004). It is particularly important to examine correlates of academic dishonesty among criminal justice and policing students, as those students convicted of academic dishonesty charges may face significant barriers to employment within legal, criminal justice and policing agencies that may require disclosure of academically dishonest behaviour as part of their staff recruitment processes.

In Australia, several studies have been conducted on the dynamics of academic dishonesty across a range of academic disciplines (e.g. Brimble and Stevenson-Clarke 2005; Marsden et al. 2005; Ogilvie and Stewart 2010). While research has been 
conducted on academic dishonesty amongst criminology students in the United States (Coston and Jenks 1998; Eskridge and Ames 1993; Lambert and Hogan 2004; Tibbetts 1998), to date no research has been conducted on academic dishonesty within the specific context of Australian university students within criminal justice and policing disciplines. This is unfortunate, as data from other countries with different socio-historical contexts may not be directly generalizable to the Australian context (Brimble and Stevenson-Clarke 2005). In addition, given the significant focus on misconduct and corruption within policing and criminal justice agencies in Australia as a result of government enquiries (see Lewis et al. 2010), the lack of research into unethical conduct among policing and criminal justice students in Australia is surprising. Although Australia currently ranks among the top 20 'cleanest' countries in the world in terms of perceived levels of public sector corruption (Transparency International 2014), the history of corruption and misconduct in Australia warrants the need to examine academically dishonest behaviour within the cohort of future policing and criminal justice professionals.

Academic dishonesty has a range of negative effects both at the institutional and individual level (Brimble and Stevenson-Clarke 2005; Clement 2001; Marsden et al. 2005; McCabe and Trevino 1993). At the institutional level, student involvement in academic dishonesty has clear potential to diminish the reputation and integrity of universities and can also threaten the economic viability of universities situated within competitive educational markets (Brimble and Stevenson-Clarke 2005; Marsden et al. 2005). Academic dishonesty also hinders the ability of universities to ensure that students who complete degrees have the knowledge and skills they require for employment or for further study (Brimble and Stevenson-Clarke 2005). At the individual level, negative effects of cheating include non-cheating students being put at a potential academic disadvantage to students who engage in academic dishonesty (McCabe and Trevino 1993). In addition to this, engagement in academic dishonesty has been linked to increased acceptance of unethical workplace behaviour (Lawson 2004; Nonis and Swift 2001), suggesting that academic misconduct may continue post-graduation. This potential continuation of unethical conduct is, of course, particularly relevant for future police and criminal justice professionals, given that their discretionary powers may have extensive impact on the lives of the client groups with which they come into contact.

The current study builds new knowledge and adds to the evidence base on academic dishonesty in a number of ways. Firstly, it examines the prevalence and predictors of academic dishonesty amongst Australian policing and criminal justice students. Secondly, it highlights a range of recommendations that academic faculties can implement in order to better prevent academic dishonesty behaviours. Thirdly, it adds to the current theoretical understanding of academic dishonesty.

\section{Defining academic dishonesty}

Within the extant empirical research, there is debate regarding what constitutes academic dishonesty (Pincus and Schmelkin 2003; Whitley and Keith-Spiegel 2002). Pavela's (1978) definition provides a useful starting point for the institutional identification and study of academic dishonesty (Lambert and Hogan 2004; Whitley and Keith-Spiegel 2002). Pavela (1978) conceptualises academic dishonesty as incorporating four main types of fraudulent and unethical conduct. Within this, the first type of academic dishonesty is cheating, 
which includes the intentional use or attempted use of unauthorised materials or information in an examination. Secondly, there is fabrication or invention of any information or citation. Thirdly, facilitation relates to behaviours that assist other students in engaging in academic dishonesty. The final form of academic dishonesty under Pavela's definition is plagiarism which refers to "the deliberate use, adoption or reproduction of ideas, words or statements of another person as one's own without acknowledgement of the author" (Pavela 1978, p.73).

Some researchers have suggested that there are other acts that fall within the umbrella of academic dishonesty (Pincus and Schmelkin 2003; Whitley and Keith-Spiegel 2002). In this regard, some have suggested that academic dishonesty includes misrepresentation which includes providing a false excuse to gain an assignment extension or deferment of an exam (Whitley and Keith-Spiegel 2002). It has also been suggested that academic sabotage, which involves deliberating hiding or destroying books in a library so that other students cannot use them, should also be incorporated into definitions of academic dishonesty (Whitley and Keith-Spiegel 2002). The current research utilises a broad definition of academic dishonesty that includes not only the four elements of Pavela's (1978) definition but also misrepresentation and academic sabotage.

\section{Individual characteristics}

A central focus in much of the academic dishonesty research has been to explore the individual characteristics of those students who are most likely to engage in academic dishonesty. Researchers have often hypothesised that the characteristics of students most likely to engage in academic dishonesty include being male and being from a non-English speaking background (e.g. Marshall and Garry 2006; McCabe and Trevino 1997). Many studies have found that male gender is a statistically significant predictor of higher likelihood of involvement in academically dishonest behaviour (Jensen et al. 2002; Kremmer et al. 2007; McCabe and Trevino 1997). Males' involvement in academic dishonesty may be explained by the gender role conflict that occurs when males are socialised into traditional roles of masculinity, underpinned by expectations of success manifested as persistent worries about personal achievement, competence, failure and career achievement (Cournoyer and Mahalik 1995; O'Neil et al. 1995). A metaanalysis conducted by Whitley et al. (1999) examining gender differences in attitudes toward and engagement in academic dishonesty found that women held significantly higher negative attitudes towards cheating than men. Results further showed that men were more likely to engage in academic dishonesty, although these gender differences were associated with a relatively small effect size. However, other studies have found no gender differences (Diekhoff et al. 1996; Roig and Caso 2005).

In contrast to these findings on gender, some more consistent results have emerged regarding the degree to which ethnicity or being from a non-English speaking background is predictive of academic dishonesty. Research has found that students from a non-English speaking background are more likely to engage in academic dishonesty (Marshall and Garry 2006) and that non-White criminology students report higher levels of academic dishonesty (Lambert and Hogan 2004). One explanation for this may be that students from minority backgrounds, particularly those with weaker English language skills, may perceive academic life to be more stressful and feel less able to cope with academic expectations compared with other students (Wan et al. 
1992). Nonetheless, there is some research to suggest that while international students are more likely to cheat on exams, they are less likely to engage in academically dishonest practices in written assignments (Kremmer et al. 2007), suggesting that there may be variations among types of academic dishonesty.

In addition to the research into the individual factors that predict academic dishonesty, researchers have also stressed that there are contextual issues that are essential to examine in the ongoing development of strategies to reduce the prevalence of academic dishonesty (Jordan 2001; McCabe and Trevino 1993). These include motivational factors, perceived seriousness and peer involvement. In addition to these factors, from a deterrence perspective certainty of detection/punishment and severity of punishment may also be important factors in explaining academic dishonesty (Ogilvie and Stewart 2010; Paternoster 1987). However, these factors are not the focus of the current study.

\section{Motivations and justifications for engaging in academic dishonesty}

It is clear that students have a wide range of motivations for engaging in academic dishonesty, with many students, including criminal justice students, reporting that academic dishonesty is justified in certain circumstances (Brimble and Stevenson-Clarke 2005; de Lambert et al. 2003; Jensen et al. 2002; Lambert and Hogan 2004; McCabe et al. 1999; Whitley and Keith-Spiegel 2002). A key qualitative study in this area conducted by McCabe et al. (1999) found that common motivations for student engagement in academic dishonesty include pressure to get higher grades, a desire to excel, lack of preparation and pressure to gain employment upon completion of study. Students within the sample also reported that academic dishonesty could be justified in certain situations including: when there are parental pressures to do well; to remain academically competitive with others students; and excessive workload or assessment standards set by lecturers and tutors. Although students may be aware of the unethical nature of academically dishonest behaviour, techniques of neutralisation offer one theoretical explanation for their justification of unethical behaviours (Sykes and Matza 1957). Examining students' self-reported reasons for engaging in academic dishonesty, Brimble and Stevenson-Clarke (2005) found that student motivations were consistent with a neutralisation framework, whereby the students rationalised their academically dishonest conduct by providing reasons relating to the difficult and time-consuming nature of the academic assessments. Interestingly, these were not the same reasons provided to academic staff, suggesting a discrepancy between students' actual reasons and the reasons provided to staff once students have been caught for academic dishonesty.

\section{Attitudes toward academic dishonesty}

Engagement in academic dishonesty has also been associated with attitudes toward such behaviour. Theoretically, the expectation is that individuals who hold antisocial attitudes are more likely to engage in antisocial conduct when provided with the situational opportunity to do so (Farrington 2005). A number of studies indicate that students may be more likely to cheat when they view cheating as not unethical or not a serious form of misconduct (Bolin 2004; Jensen et al. 2002; Salter et al. 2001; Tibbetts 1998). For example, an examination of college students' moral evaluations of cheating behaviour in the United States showed that attitudes toward academic dishonesty 
accounted for nearly $40 \%$ of the variation in academically dishonest behaviour (Bolin 2004). Similarly, examining high school and college students, Jensen et al. (2002) found that students who evaluated cheating leniently were more likely to engage in cheating behaviour themselves. Thus, attitudes may play an important role in explaining cheating behaviour.

\section{Peer involvement in academic dishonesty}

Students who overestimate peer involvement in academic misconduct may believe cheating to be the norm and therefore engage in this behaviour themselves (Conway et al. 2006). Thus, peer involvement in academic dishonesty is another contextual factor that can lead to student violations of academic integrity rules (Brimble and Stevenson-Clarke 2005; McCabe and Trevino 1997; Tibbetts 1998). This was a key finding of the research conducted by Tibbetts (1998), who found that university students studying a criminal justice major were significantly more likely to cheat if they had friends that they knew had previously engaged in or continued to engage in test cheating. Similarly, using a vignette design O’Rourke et al. (2010) found that the decision to cheat was largely determined by observation of other students' cheating behaviour within the classroom setting.

Collectively the extant research points to a number of aspects warranting investigation amongst Australian criminal justice and policing students. Firstly, academic dishonesty is more prevalent in males, those from an ethnic minority, and those with poor English language skills. Secondly, there are a range of motivations and related neutralisations employed by students to justify their engagement in academic dishonesty. Thirdly, attitudes towards academic dishonesty are related to engagement in cheating behaviours. Finally, research has also shown that if students believe that cheating behaviour is normative within their institution they are more likely to engage in academic misconduct themselves. These findings provide challenges for university administrators and academics when attempting to curb academic dishonesty within their institutions and therefore are the key points of investigation for the current study.

\section{Purpose of the study}

The findings of existing research have provided vital knowledge for universities around the world in their continuing efforts to detect and prevent academic dishonesty (Whitley and Keith-Spiegel 2002). While research has been conducted on academic dishonesty amongst American students within criminal justice faculties (e.g. Lambert and Hogan 2004; Tibbetts 1998), no research has been conducted to examine whether there are particular individual characteristics and contextual factors that predict involvement in academic dishonesty among Australian criminology students. This lack of knowledge exists despite the effects of academic dishonesty on universities and also despite the importance of preventing academic dishonesty amongst criminology students, where an academic dishonesty charge may represent a significant barrier for student employment within the legal, criminal justice system and policing sector. This study aims to begin to address these gaps and to make recommendations of the prevention of academic dishonesty amongst criminal justice and policing students. To achieve this aim, this study examines which individual and contextual factors are predictive of engagement in academic dishonesty among criminal justice and policing students in Australia. 


\section{Methodology}

\section{Data and sample}

The undergraduate criminal justice and policing students sampled for this study were enrolled at a small department within a large public university in Australia; there are 37 public and 2 private universities in Australia. The university at which the study was conducted enrols approximately 30,000 full-time equivalent (FTE) students. The university actively publicises institution-wide rules relating to the standards of academic integrity within written teaching materials, in classes and in online materials. Under these rules, a number of academically dishonest behaviours are prohibited and subject to disciplinary action. This includes minor plagiarism (e.g. inadequate referencing) and major plagiarism (e.g. submitting assignments written by someone else) on written assignments. The rules further prohibit forms of academic dishonesty in exams and tests (e.g. copying from another student). The university requires students to sign a declaration in exams and on completed assignments, stating that they have not breached the rules regarding academic integrity.

Participants were recruited using a purposive sampling strategy. Under this approach, students attending a lecture for an undergraduate research methods course were invited by their lecturer to participate in a research project on academic dishonesty. This was a core course, and all students were required to complete the course in the second or third year of their degree. The sample was chosen as it contained students who had been studying at the university for at least one year, allowing time for the students to gain an understanding of the university rules as well as an opportunity to engage in or observe academic dishonesty in the various subjects they had studied during this time. The course had 172 students enrolled in an on-campus study mode, of which 79 completed the survey. Respondents with completed data on all of the variables were included in the analyses $(n=72$, representing $91.1 \%$ of the original sample). It is recognised that those most likely to display academic difficulties may not be included in the sample as it is possible that only the most diligent and conscientious students attend lectures. Therefore, any estimates of association will be conservative.

As an incentive for participation, students were offered a non-coercive reward of $3 \%$ extra academic credit in the subject that they were studying. Students who did not wish to participate were given the option of completing another short research task to gain the $3 \%$ extra academic credit. Data were collected by administering a modified version of the Academic Dishonesty Survey (McCabe 2003) which is available from the corresponding author. In compliance with Australian National Ethical Guidelines, the questionnaire had a coversheet that outlined the nature of the research project, provided assurances that participant confidentiality and anonymity would be maintained, and provided contact details for the Principal Researcher and the University Ethics Committee.

\section{Measures}

\section{Demographic variables}

Two demographic variables were included in the current study: gender and language background. Respondents who indicated that English was not their first language were classified as coming from a non-English speaking background (NESB). 


\section{Academic dishonesty engagement}

To measure academic dishonesty, the current study utilised the Academic Dishonesty Scale of the Academic Dishonesty Survey (McCabe 2003). The scale utilised asked participants about their involvement in 25 different behaviours considered to be academic dishonesty. The response categories included 1 (never), 2 (once), and 3 (more than once). The scores for the 25 items were summated to create an overall academic dishonesty score for each participant. Cronbach's alpha revealed adequate internal consistency for the items on the scale $(\alpha=0.65)$. The scale displayed a positive skew and therefore a $\log$ transformation of the scale was used in the preliminary analyses (McCabe and Trevino 1993; Tabachnick and Fidell 2007). However, the use of the transformed scale did not make a meaningful difference to the pattern of results, therefore the untransformed scale is presented for ease of interpretation.

\section{Justifications for engaging in academic dishonesty}

Student views regarding the circumstances under which academic dishonesty is justified were also assessed using a measure from the Academic Dishonesty Survey (McCabe 2003). This measure contains 12 different potential reasons for engaging in academic dishonesty and participants were asked to indicate whether they agreed that the academic misconduct was justified in each of the listed circumstances. The responses were coded into a dichotomous variable. Respondents who agreed with at least one of the items on the scale were classified as holding justifications for engaging in academic dishonesty. Thus, this measure provides an indication of students' justifications for academically dishonest conduct.

\section{Perceived seriousness of academic dishonesty}

Given that delinquent behaviour may be more prevalent among individuals who hold favourable attitudes toward this type of conduct (e.g. Farrington 2005), it is important to measure students' attitudes toward academic dishonesty. Student views on the degree to which academic dishonesty is a serious form of misconduct were assessed using 25 items from the Academic Dishonesty Survey (McCabe 2003). Participants were asked to rate whether 25 different forms of academic dishonesty were serious forms of cheating. The responses were reported on a 5-point Likert scale ranging from 1 (strongly disagree) to 5 (strongly agree). The scores for the items were summated to create an overall academic dishonesty seriousness score for each participant. Cronbach's alpha revealed high internal consistency for the items on the scale $(\alpha=0.95)$. As the scale displayed a negative skew it was subject to reflection and square root transformation (Tabachnick and Fidell 2007). However, similar to the academic dishonesty measure, the use of the transformed scale did not make a meaningful difference to the pattern of results, therefore the untransformed scale is presented for ease of interpretation.

\section{Perceived peer engagement in academic dishonesty}

Students may be more likely to engage in academic dishonesty if they believe this behaviour to be the norm (Conway et al. 2006). To measure the perceived extent of other students' engagement in academic misconduct, students were asked how frequently they believed any of the following occurred on campus: plagiarism, inappropriate 
sharing in group assignments, cheating during tests/examinations, and falsifying research data. This measure of perceptions of peer involvement in academic dishonesty is consistent with those used in the field (e.g. Kremmer et al. 2007; McCabe and Trevino 1993). While not a direct measure of peer involvement, it provides a gauge of the individual's context and whether they believe academic dishonesty is normative. The items were taken from the Academic Dishonesty Survey (McCabe 2003). The responses were reported on a 5-point Likert scale ranging from 1 (never) to 5 (very often). The scores for the three items were summated to create an overall perceived peer engagement score for each participant. Cronbach's alpha revealed adequate internal consistency for the items on the scale $(\alpha=0.74)$. The scale was normally distributed.

\section{Analysis}

All respondents with complete data were included in the analyses, resulting in a total sample size of 72 (91.1\% of the original sample). No variable had missing data of more than $5 \%$. An inspection of the missing cases revealed that they displayed similar demographic characteristics to the respondents included in the analyses. Data were analysed using SPSS Statistical Software, version 21. First, descriptive statistics were generated. Second, a multiple regression model was estimated to establish the relative predictive effects of individual and contextual factors on academic dishonesty engagement. VIF and tolerance values revealed no issues of collinearity in the regression model. Inspection of the residuals confirmed that the data met the general assumptions of multiple regression models (e.g. normality, linearity, homoscedasticity). Due to the relatively small sample size adjusted R squared is reported (Tabachnick and Fidell 2007).

\section{Results}

\section{Descriptive statistics}

Results in Table 1 show that two-thirds of respondents were female and that the majority of respondents reported coming from a non-English speaking background. Results further show that respondents scored an average of 28.88 on the academic dishonesty scale. Closer examination of this variable revealed that the most commonly reported

Table 1 Descriptive statistics $(n=72)$

\begin{tabular}{lcccccc}
\hline Variable & Number & Percent & M & SD & Min & Max \\
\hline Gender & 22 & 30.56 & & & \\
$\quad$ Male & 50 & 69.44 & & & \\
$\quad$ Female & & & & & & \\
Language background & 65 & 90.28 & & & & \\
$\quad$ ESB & 7 & 9.72 & & & & \\
$\quad$ NESB & & & 28.88 & 3.25 & 25 & \\
Academic dishonesty engagement & 24 & 33.33 & & & & \\
Justifications & 48 & 66.67 & & & & \\
$\quad$ No justifications & & & 104.46 & 14.45 & 31 \\
$\quad$ At least one justification & & & 12.24 & 2.69 & 4 & 19 \\
Perceived seriousness & & & & & \\
Perceived peer engagement & & & & & & \\
\hline
\end{tabular}


acts of academic dishonesty included sharing an assignment with others to use as an example (55.56\%), working on an individual assignment together with others $(48.61 \%)$, and copying a few sentences from a written source without citing (44.44\%). Results in Table 1 further show that two-thirds of respondents believed academic dishonesty to be justified under certain circumstances. The most common justifications included time pressure (48.61 \%), fear of failure (48.61\%), and to pass a course (41.67 \%). As per Table 1, respondents scored on average 104.46 on the scale measuring perceived seriousness of academic dishonesty. The least serious acts (as measured by the prevalence rate of respondents disagreeing or strongly disagreeing) included: working on an individual assignment together with others (43.06 \%), sharing an assignment with others to use as an example (37.50\%), and copying a friend's computer program (19.44 \%). Finally, Table 1 reveals a mean perceived peer engagement score of 12.24. In particular, respondents most commonly reported that they believed inappropriate sharing on group assignments was occurring often or very often on campus $(61.11 \%)$.

\section{Multivariate analyses}

A multiple regression was performed to examine which individual and contextual factors were predictive of self-reported academic dishonesty. As shown in Table 2, the model accounted for significant variance $(26.20 \%)$ in academic dishonesty engagement $(F(5,66)=6.04, p=0.001)$. Inspection of the coefficients revealed that males scored significantly higher on the academic dishonesty scale than females. In contrast, language background did not make a significant contribution to the model. Of the contextual factors, only two were statistically significant. The coefficients revealed that a stronger belief in academic dishonesty being justified significantly predicted higher student involvement in academic dishonesty, as did viewing academic dishonesty as less serious. In contrast, perceived peer engagement in academic dishonesty was not found to be a statistically significant predictor of self-reported academic dishonesty involvement.

\section{Discussion}

The primary aim of this study was to explore the predictors of academic dishonesty amongst a sample of criminal justice and policing students enrolled at an Australian university. Drawing upon data obtained from a questionnaire, the results suggest that

Table 2 Regression of gender, language background, justifications, perceived seriousness and peer engagement on academic dishonesty $(n=72)$

\begin{tabular}{lccccc}
\hline Variable & B & S.E. & Beta & t & $p$ \\
\hline Individual factors & & & & & \\
$\quad$ Gender (1 = male) & 1.67 & 0.76 & 0.24 & 2.21 & 0.031 \\
$\quad$ Language background (1 = NESB) & 1.02 & 1.15 & 0.09 & 0.89 & 0.379 \\
Contextual factors & & & & & \\
$\quad$ Justifications & 1.80 & 0.75 & 0.26 & 2.41 & 0.019 \\
$\quad$ Perceived seriousness & -0.06 & 0.03 & -0.27 & -2.45 & 0.017 \\
$\quad$ Perceived peer engagement & 0.20 & 0.13 & 0.17 & 1.62 & 0.110 \\
Constant & 30.93 & 3.16 & & 9.78 & 0.000 \\
Adjusted $R^{2}$ & 0.262 & & & & \\
\hline
\end{tabular}


male gender is an individual characteristic predictive of higher involvement in academic dishonesty. This is consistent with research from Australia and other countries (Jensen et al. 2002; Kremmer et al. 2007) as well as research on criminal justice students (Lambert and Hogan 2004). The results further suggest that considering academic dishonesty to be justified under certain circumstances is predictive of academic dishonesty engagement. This is consistent with previous research, which shows that students report a number of motivations and justifications for engaging in this type of behaviour (Brimble and Stevenson-Clarke 2005; Jensen et al. 2002). In addition, the results show that viewing academic dishonesty as less serious is a contextual factor predictive of academic dishonesty, similar to other research findings (Bolin 2004; Tibbetts 1998). Thus, based on the results of the current study and the research literature, it appears as though the predictors of academic dishonesty are relatively similar for the sample of Australian criminal justice and policing students used in the current research and university/college students from other disciplines and countries.

Nonetheless, a couple of interesting findings were observed. First, perceptions of peer engagement in academic dishonesty was not found to be predictive of student behaviour in the current study, despite the research literature frequently reporting peer behaviour as one of the main predictors of academic dishonesty (Brimble and Stevenson-Clarke 2005; McCabe and Trevino 1997; Tibbetts 1998). One speculative explanation for this may be that criminal justice and policing students are not influenced by peer behaviour to the same extent as students in other disciplines but this requires further research. One existing study suggests that this is not the case; criminal justice students were more strongly affected by peer behaviour compared with non-criminal justice students (Tibbetts 1998). Another explanation may be that the internalisation of perceived social norms is more influential than the actual behaviour displayed by peers. Thus, exposure to peer behaviour may instil a belief system condoning the use of dishonest behaviour in academic settings (e.g. Akers 1998), suggesting that the influence of peer involvement may be indirectly linked to behaviour through the mediating effect of attitudes. Further research is needed to examine these potential explanations.

In addition, language background was not found to be predictive of engagement in academic dishonesty in the current study, despite prior research suggesting it might be (Marshall and Garry 2006). There may be a simple explanation for this. Rather than measuring English language proficiency the current study examined whether or not respondents came from an English-speaking background. However, having English as a second language does not necessarily equate to low English proficiency. Rather, a range of individual and contextual factors has been shown to influence second language acquisition (e.g. Ellis 1997). As most Australian universities require a certain level of English competency for admission to their academic courses/degrees (e.g. overall IELTS band score of 6.0, indicating a competent user), it may be that the language skills in the current sample were moderately high despite some respondents coming from non-English speaking backgrounds. Since it has been suggested that students with weaker English skills are less likely to cope with academic expectations and experience higher levels of academic stress than other students (Wan et al. 1992), future research will need to examine further whether level of English proficiency is predictive of academically dishonest conduct.

Several policy implications flow from the findings of this research. The findings support the continuation of existing policies as well as the development of new ones. 
Importantly, faculties offering criminology, criminal justice and policing degrees should implement a range of practical strategies in order to prevent academic misconduct and its associated effects on individuals, the student body and university institutions. In particular, universities need to develop strategies to ensure students understand that academic dishonesty is a serious form of misconduct, and that the university is undertaking steps to detect academic dishonesty. The results of this research suggest that students are more likely to engage in academic dishonesty if they view it as a less serious form of academic misconduct. This is consistent with theories proposing that individuals who hold antisocial attitudes are more perceptive to engaging in delinquent behaviour when the opportunity to do so arises (e.g. Farrington 2005). Other research has found lower acceptability of cheating and plagiarism to be predicted by students' understanding of academic dishonesty policies (Kuntz and Butler 2014). Thus, one means to address students' lenient attitudes would be to increase their awareness of university policies on what constitutes academic dishonesty.

However, although the current sample was drawn from a university that actively publicises institution-wide rules relating to the standards of academic integrity, results from other research suggest that some students are not aware of university policies regarding dishonesty (Jordan 2001). This is concerning because it may be that some students are unknowingly engaging in acts that constitute academic dishonesty. There are a number of effective ways to promote student awareness of academic integrity policies, including ensuring that information is made easily accessible online through a centralised university website (Bretag et al. 2011b). However, research examining online academic integrity policies within Australian universities suggests that this is not always achieved, as several policies often co-exist and are sometimes not up-to-date (Bretag et al. 2011b). In addition, teaching staff should also place emphasis on providing students with examples of what constitutes academic dishonesty within the classroom setting and may for example convene specific sessions with students on these issues (Blum 2009). These sessions may not only assist by providing students with better knowledge of policy but also provide an opportunity for policy improvement as students could be asked for constructive feedback on whether they view existing policies as effective or fair and for their views on ways in which policy could be improved (Blum 2009).

Another way that many universities currently convey the seriousness of academic dishonesty to students is through the imposition of penalties ranging from a reduced grade to expulsion from a degree program. Although not explicitly examined in the current study, penalties enforced against students for academic dishonesty may serve a deterrent function (McCabe and Trevino 1997; Michaels and Miethe 1989). The theoretical argument is that perceptions of the certainty of detection and severity of punishment serve as deterrents for students to engage in academic dishonesty (Paternoster 1987). However, research has generated mixed results, with some finding an effect of severity (McCabe and Trevino 1993), some finding an effect of certainty but not severity (Nagin and Pogarsky 2003), and others finding no effect for either construct (Cochran et al. 1999) on academic dishonesty.

Thus, the publication and administration of penalties should not be the sole means by which students are alerted that academic dishonesty is a serious form of misconduct that has consequences. In fact, Roberts-Cady (2008) notes that by implementing such policies, faculties are merely manipulating student behaviour as opposed to addressing 
students' ethical decision making. Instead, faculties should focus more attention on increasing moral development through incorporation of moral philosophy and ethical discussion into the curriculum (Davis et al. 2009; Roberts-Cady 2008). Yet, only onethird of universities in Australia have developing student integrity as their main focus (Bretag et al. 2011a). There is some evidence to suggest that including ethics components into university degrees reduces illicit collaborations between students (Reisenwitz 2012). The inclusion of ethics into the curriculum would convey to students that academic dishonesty is not only serious because it results in penalties that can jeopardise future study and employment, but also that it represents unethical behaviour toward other students and the university. Consistent with Kohlberg's theory of moral development, the incorporation of moral education in the academic curriculum provides students with the scaffold with which to progress to higher levels of moral reasoning (Kohlberg and Hersh 1977). Furthermore, Wikström et al. (2012) argue that people's moral actions are action alternatives that operate in a particular situation. A situation that discourages academic dishonesty via well established moral norms against academic dishonesty and enforcement of these norms is more likely to lead to individuals engaging in actions in line with these norms. The development of moral reasoning is particularly relevant for criminal justice and policing graduates, since they may exercise a large amount of discretionary powers as part of their prospective work roles.

University efforts to prevent academic dishonesty should further place emphasis on trying to break down student beliefs that academic dishonesty can be justified. According to neutralisation theory, individuals who would normally experience guilt when engaging in delinquent behaviour can effectively 'neutralise' this guilt by engaging in a number of methods, such as denying responsibility and denying that any injury has been caused (Sykes and Matza 1957). Consistent with previous research (e.g. Brimble and Stevenson-Clarke 2005), the results of the current research suggest that a substantial number of students viewed academic dishonesty as justified because of time pressure, fear of failure, or in order to pass a course. To circumvent these neutralisations it is necessary: to provide cognitive-based approaches for students; for students to accept responsibility; and to neutralise the neutralisations (adapted from Maruna and Copes 2005). One way of providing cognitive-based approaches and encouraging students to accept responsibility would be for universities and academic staff to make greater efforts to link students to sources of support within the university. For example, where possible, students could be informed by academic staff that they can access student counselling services on campus in order to manage course related stress and anxiety, a potential motivational factor for cheating. Furthermore, to minimise risk of academic misconduct, students who are suffering time pressures and work long hours in paid employment should be encouraged to attend time and study management courses that aim to increase student productivity. Advertising is another measure that could also be implemented to reduce student perceptions of academic dishonesty as justified (i.e. as a means of neutralising the neutralisations). This includes using specifically developed websites, campus posters and pamphlets that identify the most commonly used neutralisations. These advertisements should convey to students that academic dishonesty is never justified on the basis of these neutralisations. Furthermore, it should be made clear that it is unethical and that there are 
negative consequences of academic dishonesty for individuals, the student body and university institutions.

\section{Limitations}

In interpreting the findings of this study, two key limitations need to be taken into consideration. A major limitation of this study relates to the sample of participants. The sample was relatively small with a low prevalence of students from non-English speaking backgrounds. In these circumstances, the findings of this study may lack generalisability and needs to be replicated by other researchers utilising larger samples and over-sampling students from non-English speaking backgrounds. In addition, the use of a sample of students attending lectures provides a potential bias, as more diligent and conscientious students may be more likely to attend class. Thus, it is likely that the results from this study are conservative.

Another potential limitation of this study relates to the measure of academic dishonesty used. To measure academic dishonesty, this study required student participants to self-report how many times they had engaged in 25 different types of academic dishonesty and this was used to create an overall academic dishonesty score for each participant. A concern with this measure is that it may be too complex to expect students to remember whether they had ever engaged in different types of academic dishonesty. There is also the potential for bias on the self-reports of academic dishonesty of the participants. As argued by Farrington and Ttofi (2014), when discussing the disclosure of offending behaviour, self-reports open up the possibility of both exaggeration and concealment. However, the advantage of the measure used in this study is that it provides a strong indication of student involvement in a wide range of different behaviours that would constitute academic misconduct at many universities.

\section{Directions for future research}

At present, limited research has examined the prevalence and predictors of academic dishonesty within Australian universities. This is unfortunate, as data from other countries with different socio-historical contexts may not be directly generalisable to the Australian context (Brimble and Stevenson-Clarke 2005). Furthermore, there is a need to build upon the results of this study regarding academic dishonesty amongst policing and criminal justice students in Australia. This is particularly relevant given the level of attention afforded corruption and misconduct issues within the criminal justice sector in Australia. Future studies should test the findings of this research using a larger and more representative sample in order to increase our understanding of academic dishonesty amongst Australian students studying criminal justice and policing. Additionally, future research should also place emphasis on continuing to unpack the important relationships between individual and contextual factors and levels of academic dishonesty (McCabe et al. 2001), including examining causal relationships. Furthermore, further research is also required to address the task of examining preventative methods used in university institutions to reduce levels of academic dishonesty. This research should utilise strong experimental designs that compare levels of academic dishonesty in universities with and without particular prevention strategies in place. It is only through the maintenance of a strong research agenda on academic dishonesty that the causes and best practice for reducing its incidence both within and outside the discipline of criminology will be better understood. 


\section{Competing interests}

The authors declare that they have no competing interests.

\section{Authors' contributions}

Both authors contributed extensively to the work presented in this manuscript. TRM designed the research plan and organised the study. LE ran analyses and drafted the manuscript. Both authors read and approved the final manuscript. Research assistants Denise Foster and Michael Cerruto contributed to the data entry and literature searches.

\section{Authors' information}

Li Eriksson, PhD, is a Lecturer in the School of Criminology and Criminal Justice, Griffith University. Her research forms part of the Australian Homicide Project, which is a national ARC Discovery project examining developmental and situational pathways to homicide. Her research interests include violence, intimate partner homicide, filicide and criminological theory. Before joining Griffith University, Li worked as a Research Analyst for the Swedish National Council for Crime Prevention.

Tara Renae McGee, PhD, is a Senior Lecturer in the School of Criminology and Criminal Justice, Griffith University. Her research interests focus on the development of offending over the life-course. Her current project is a longitudinal study examining the third generation of an Australian birth cohort. Tara is a founding co-editor of the Journal of Developmental and Life-Course Criminology, with Paul Mazerolle.

\section{Acknowledgements}

The authors would like to thank Michael Cerruto and Denise Foster for their contributions to the research project and earlier versions of the paper. The authors also wish to thank the editor and anonymous reviewers for their helpful feedback on this paper.

Received: 13 May 2014 Accepted: 30 April 2015

Published online: 08 August 2015

\section{References}

Akers R (1998) Social learning and social structure: a general theory of crime and deviance. Northeastern University Press, Boston

Allen J, Fuller D, Luckett M (1998) Academic integrity: behaviors, rates, and attitudes of business students toward cheating. J Mark Educ 20:41-52

Blum SD (2009) My word! Plagiarism and college culture. Cornell University Press, Ithaca

Bolin AU (2004) Self-control, perceived opportunity, and attitudes as predictors of academic dishonesty. J Psychol 138:101-114

Bretag T, Mahmud S, East J, Green M, James C, McGowan U, Partridge L, Walker R, Wallace M (2011a) Academic integrity standards: a preliminary analysis of the academic integrity policies at Australian Universities Proceedings of AuQF 2011: demonstrating quality. AuQF, Melbourne

Bretag T, Mahmud S, Wallace M, Walker R, James C, Green M, East J, McGowan U, Partridge L (2011b) Core elements of exemplary academic integrity policy in Australian higher education. Int J Educ Integr 7:3-12

Brimble M, Stevenson-Clarke P (2005) Perceptions of the prevalence and seriousness of academic dishonesty in Australian universities. Aust Educ Res 32:19-44

Clement MJ (2001) Academic dishonesty: to be or not to be? J Crim Just Educ 12:253-270

Cochran JK, Chamlin MB, Wood PB, Sellers CS (1999) Shame, embarrassment, and formal sanction threats: extending the deterrence/rational choice model to academic dishonesty. Sociol Inq 69:91-105

Conway JM, Hard SF, Moran AC (2006) Faculty and college student beliefs about the frequency of student academic misconduct. J High Educ 77:1058-1080

Coston CTM, Jenks DA (1998) Exploring academic dishonesty among undergraduate criminal justice majors: a research note. Am J Crim Justice 22:235-248

Cournoyer RJ, Mahalik JR (1995) Cross-sectional study of gender role conflict: examining college-aged and middle-aged men. J Couns Psychol 42:11-19

Davis SF, Drinan PF, Bertram Gallant T (2009) Cheating in school: what we know and what we can do. Wiley-Blackwell, Malden, MA

de Lambert K, Ellen N, Taylor L (2003) Cheating-what is it and why do it: a study in New Zealand tertiary institutions of the perceptions and justifications for academic dishonesty. J Am Acad Bus Camb 3:98-103

Diekhoff G, LaBeff E, Clark R, Williams L, Francis B, Haines V (1996) College cheating: ten years later. Res High Educ 37:487-502

Ellis R (1997) Second language acquisition. Oxford University Press, Oxford

Eskridge C, Ames GA (1993) Attitudes about cheating and self-reported cheating behaviors of criminal justice majors and noncriminal justice majors: a research note. J Crim Just Educ 4:65-78

Farrington DP (2005) The Integrated Cognitive Antisocial Potential (ICAP) theory. In: Farrington DP (ed) Integrated developmental and life-course theories of offending. Vol. 14. Transaction Publishers, New Brunswick, NJ, pp 73-92

Farrington DP, Ttofi M (2014) Editorial: criminal careers in self-reports compared with official records. Crim Behav Ment Health 24:225-228

Hrabak M, Vujaklija A, Vodopivec I, Hren D, Marusic M, Marusic A (2004) Academic misconduct among medical students in a post-communist country. Med Educ 38:276-285

Iyer R, Eastman JK (2006) Academic dishonesty: are business students different from other college students? J Educ Bus $82: 101-110$

Jensen LA, Arnett JJ, Feldman SS, Cauffman E (2002) It's wrong, but everybody does it: academic dishonesty among high school and college students. Contemp Educ Psychol 27:209-228 
Jordan AE (2001) College student cheating: the role of motivation, perceived norms, attitudes, and knowledge of institutional policy. Ethics Behav 11:233-247

Kohlberg L, Hersh RH (1977) Moral development: a review of the theory. Theory Pract 16:53-59

Kremmer ML, Brimble M, Stevenson-Clarke P (2007) Investigating the probability of student cheating: the relevance of student characteristics, assessment items, perceptions of prevalence and history of engagement. Int J Educ Integr 3:3-17

Kuntz JRC, Butler C (2014) Exploring individual and contextual antecedents of attitudes toward the acceptability of cheating and plagiarism. Ethics Behav 24:478-494

Lambert EG, Hogan NL (2004) Academic dishonesty among criminal justice majors: a research note. Am J Crim Justice 29:1-22

Lawson RA (2004) Is classroom cheating related to business students' propensity to cheat in the "real world"? J Bus Ethics 49:189-199

Lewis C, Ransley J, Homel R (2010) The Fitzgerald legacy: reforming public life in Australia and beyond. Australian Academic Press, Bowen Hills, Qld

Marsden H, Carroll M, Neill JT (2005) Who cheats at university? A self-report study of dishonest academic behaviours in a sample of Australian university students. Aust J Psychol 57:1-10

Marshall S, Garry M (2006) NESB and ESB students' attitudes and perceptions of plagiarism. Int J Educ Integr 2:26-37

Maruna S, Copes H (2005) What have we learned from five decades of neutralization research? Crime Justice 32:221-320

McCabe DL (2003) 2003 spring semester Kansas State University academic dishonesty survey study. Unpublished instrument. (Contact authors for copy of instrument).

McCabe DL, Trevino LK (1993) Academic dishonesty: honor codes and other contextual influences. J High Educ 64:522-538

McCabe DL, Trevino LK (1996) What we know about cheating in college: longitudinal trends and recent developments. Change 28:29-33

McCabe DL, Trevino LK (1997) Individual and contextual influences on academic dishonesty: a multicampus investigation. Res High Educ 38:379-396

McCabe DL, Trevino LK, Butterfield KD (1999) Academic integrity in honor code and non-honor code environments: a qualitative investigation. J High Educ 70:211-234

McCabe DL, Trevino LK, Butterfield KD (2001) Cheating in academic institutions: a decade of research. Ethics Behav 11:219-232

McCabe DL, Feghali T, Abdallah H (2008) Academic dishonesty in the Middle East: individual and contextual factors. Res High Educ 49:451-467

Michaels JW, Miethe TD (1989) Applying theories of deviance to academic cheating. Soc Sci Q 70:870-885

Nagin DS, Pogarsky G (2003) An experimental investigation of deterrence: cheating, self-serving bias, and impulsivity. Criminology 41:167-194

Nonis S, Swift C (2001) An examination of the relationship between academic dishonesty and workplace dishonesty: a multicampus investigation. J Educ Bus 77:69-77

O'Neil JM, Good GE, Holmes S (1995) Fifteen years of theory and research of men's gender role conflict: new paradigms for empirical research. In: Levant RF, Pollack WS (eds) A new psychology of men. BasicBooks, New York, NY

O'Rourke J, Barnes J, Deaton A, Fulks K, Ryan K, Rettinger DA (2010) Imitation is the sincerest form of cheating: the influence of direct knowledge and attitudes on academic dishonesty. Ethics Behav 20:47-64

Ogilvie J, Stewart A (2010) The integration of rational choice and self-efficacy theories: a situational analysis of student misconduct. Aust New Zeal J Criminol 43:130-155

Paternoster R (1987) The deterrent effect of the perceived certainty and severity of punishment: a review of the evidence and issues. Justice Q 4:173-217

Pavela G (1978) Judicial review of academic decisionmaking after Horowitz. NOLPE School Law Journal 8:55-75

Pincus HS, Schmelkin LP (2003) Faculty perceptions of academic dishonesty: a multidimensional scaling analysis. J High Educ 74:196-209

Reisenwitz TH (2012) Can a business ethics course affect academic dishonesty? Acad Educ Leader J 16:115-129

Roberts-Cady S (2008) The role of critical thinking in academic dishonesty policies. Int J Educ Integr 4:60-66

Roig M, Caso M (2005) Lying and cheating: fraudulent excuse making, cheating, and plagiarism. J Psychol 139:485-494

Salter SB, Guffey DM, McMillan JJ (2001) Truth, consequences and culture: a comparative examination of cheating and attitudes about cheating among U.S. and U.K. students. J Bus Ethics 31:37-50

Sykes GM, Matza D (1957) Techniques of neutralization: a theory of delinquency. Am Sociol Rev 22:664-670

Tabachnick BG, Fidell LS (2007) Using multivariate statistics, 5th edn. Pearson/Allyn \& Bacon, Boston

Tibbetts SG (1998) Differences between criminal justice majors and noncriminal justice majors in determinants of test cheating intentions. J Crim Just Educ 9:81-94

Transparency International (2014) Corruption perception index 2014. Transparency International, Berlin

Wan TY, Chapman DW, Biggs DA (1992) Academic stress of international students attending U.S. universities. Res High Educ 33:607-623

Whitley BE, Keith-Spiegel P (2002) Academic dishonesty: an educator's guide. Lawrence Erlbaum Associates, Mahwah, NJ

Whitley BE Jr, Nelson AB, Jones CJ (1999) Gender differences in cheating attitudes and classroom cheating behavior: a meta-analysis. Sex Roles 41:657-680

Wikström POH, Oberwittler D, Treiber K, Hardie B (2012) Breaking rules: the social and situational dynamics of young people's urban crime. Oxford University Press, Oxford 